OPEN ACCESS

Edited by:

Ursula Grohmann,

University of Perugia, Italy

Reviewed by:

Thomas Serwold,

Joslin Diabetes Center and Harvard Medical School, United States

Makoto Miyara,

Hôpital Pitié-Salpêtrière, France

*Correspondence:

Flora Zavala

flora.zavala@inserm.fr

Maud D'Aven

m.daveni-piney@chru.nancy.fr

${ }^{+}$These authors have contributed equally to this work

Specialty section:

This article was submitted to Immunological Tolerance and Regulation,

a section of the journal

Frontiers in Immunology

Received: 16 September 2020 Accepted: 31 December 2020 Published: 12 February 2021

Citation:

D'Aveni M, Notarantonio A-B, Agbogan VA, Bertrand A, Fouquet G, Gastineau P, Garfa-Traoré $M$,

De Carvalho M, Hermine O, Rubio M-T and Zavala F (2021) Mobilized Multipotent Hematopoietic Progenitors Promote Expansion and Survival of Allogeneic Tregs and Protect Against Graft Versus Host Disease.

Front. Immunol. 11:607180. doi: 10.3389/fimmu.2020.607180

\section{Mobilized Multipotent Hematopoietic Progenitors Promote Expansion and Survival of Allogeneic Tregs and Protect Against Graft Versus Host Disease}

\author{
Maud D'Aveni ${ }^{1,2 *}$, Anne-Béatrice Notarantonio ${ }^{1,2+}{ }^{2}$, Viviane A. Agbogan ${ }^{3 \dagger}$, \\ Allan Bertrand ${ }^{2}$, Guillemette Fouquet ${ }^{4}$, Pauline Gastineau ${ }^{3}$, Meriem Garfa-Traoré ${ }^{5}$, \\ Marcelo De Carvalho ${ }^{2,6}$, Olivier Hermine ${ }^{4}$, Marie-Thérèse Rubio ${ }^{1,2}$ and Flora Zavala ${ }^{3 *}$ \\ 1 Université de Lorraine, CHRU Nancy, Hematology Department, Nancy, France, ${ }^{2}$ Université de Lorraine, UMR 7365 CNRS, \\ IMoPA, Nancy, France, ${ }^{3}$ Department of Immunology, Infectiology and Haematology, Université de Paris, Inserm U1151, \\ CNRS UMR 8253, Institut Necker Enfants Malades (INEM), Paris, France, 4 Université de Paris, INSERM UMR 1163, Imagine \\ Institute, Laboratory of Cellular and Molecular Mechanisms of Hematological Disorders and Therapeutic Implications, Paris, \\ France, ${ }^{5}$ Université de Paris, SFR Necker-UMS 3633/US24-Structure Fédérative de Recherche Necker, Plateforme \\ d'Imagerie Cellulaire, Paris, France, 6 Université de Lorraine, CHRU Nancy, Immunology Department, Nancy, France
}

Allogeneic Hematopoietic Stem Cell Transplantation (Allo-HSCT) is routinely performed with peripheral blood stem cells (PBSCs) mobilized by injection of G-CSF, a growth factor which not only modulates normal hematopoiesis but also induces diverse immature regulatory cells. Based on our previous evidence that G-CSF-mobilized multipotent hematopoietic progenitors (MPP) can increase survival and proliferation of natural regulatory $T$ cells (Tregs) in autoimmune disorders, we addressed the question how these cells come into play in mice and humans in an alloimmune setting. Using a C57BL/6 mouse model, we demonstrate that mobilized MPP enhance the immunosuppressant effect exerted by Tregs, against alloreactive T lymphocytes, both in vitro and in vivo. They do so by migrating to sites of allopriming, interacting with donor Tregs and increasing their numbers, thus reducing the lethality of graft-versus-host disease (GVHD). Protection correlates likewise with increased allospecific Treg counts. Furthermore, we provide evidence for a phenotypically similar MPP population in humans, where it shares the capacity to promote selective Treg expansion in vitro. We postulate that G-CSF-mobilized MPPs might become a valuable cellular therapy to expand donor Tregs in vivo and prevent GVHD, thereby making allo-HSCT safer for the treatment of leukemia patients.

Keywords: allogeneic HSCT, graft versus host disease, mobilization, multipotent progenitors, regulatory T cells, expansion, alloreactivity, mixed lymphocyte reaction 


\section{INTRODUCTION}

Allogeneic Hematopoietic Stem Cell Transplantation (allo-HSCT) is the only therapy that can cure some hematological malignancies resistant to standard anti-cancer treatment. Its success relies on the capacity of donor $\mathrm{T}$ cells to eliminate residual tumor cells, called the Graft-versus-Tumor or GVT effect. The drawback is that donor T cells also target alloantigens expressed on the cells of the recipient's organs, which leads to life-threatening complications, resulting in graft-versus-host disease (GVHD). Administration of Granulocyte Colony Stimulating Factor (G-CSF) is routinely used for allo-HSCT as a procedure to mobilize and harvest peripheral blood stem cells (PBSC) from healthy donors. Even though PBSC comprise a higher proportion of $\mathrm{T}$ cells than bone marrow (BM) allografts, they do not increase the incidence of acute graft-versus-host disease (GVHD) (1). To explain this paradox, we and other investigators have demonstrated that mobilization with G-CSF induces myeloidderived suppressor cells (MDSCs) capable of reducing alloreactive T lymphocyte proliferation (2). Among these, some subsets have been associated with a lower incidence of acute GVHD. Unfortunately, in the context of alloimmunity, suppressing conventional $\mathrm{T}$ cells could enhance infection and relapse incidence (3). This adverse effect led to the implementation of an alternative strategy to enhance the contribution of regulatory $\mathrm{T}$ cells (Tregs). It has indeed been reported that freshly isolated donor Tregs $(4,5)$ or ex vivo expanded Tregs $(6)$ added to donor $\mathrm{CD}^{+} \mathrm{T}$ cells early after allo-HSCT, reduced GVHD, while maintaining the GVT effect. We knew also that G-CSF could mobilize murine $\mathrm{CD} 117^{+} \mathrm{Sca}-1^{+} \mathrm{CD} 34^{+} \mathrm{CD} 11 \mathrm{~b}^{- \text {low }}$ multipotent progenitor precursor cells (mobMPP), which promoted, in turn, the expansion of regulatory $\mathrm{T}$ cells. The latter prevented spontaneous autoimmune type 1 diabetes in the NOD mouse model $(7,8)$ and modulated experimental autoimmune encephalomyelitis (EAE) in the C57BL6/J mouse model (9). These findings prompted us to investigate whether mobMPP could likewise contribute to Treg expansion during allo-HSCT. Having confirmed that in vitro these progenitors did effectively enhance Treg survival and proliferation in both mice and humans, we examined whether they could protect recipient mice from acute GVHD and improve their survival through expansion of natural allo-antigen-specific donor Tregs early after allo-HSCT. Furthermore, we verified whether human GCSF-mobilized MPP shared similar properties.

\section{MATERIALS AND METHODS}

\section{Mice}

$\mathrm{BALB} / \mathrm{cJ}\left(\mathrm{H}^{\mathrm{d}}{ }^{\mathrm{d}}\right), \mathrm{C} 3 \mathrm{H} / \mathrm{HeJ}\left(\mathrm{H} 2^{\mathrm{d}}\right)$ and $\mathrm{C} 57 \mathrm{BL} 6 / \mathrm{J}\left(\mathrm{H}_{2}^{\mathrm{b}}\right)$ mice were purchased from Janvier (Le Genest Saint Isle, France). Congenic (CD45.1) C57BL6/J ( $\mathrm{H}^{\mathrm{b}}$ ), Foxp3 ${ }^{\mathrm{GFP}}-\mathrm{C} 57 \mathrm{BL} 6 / \mathrm{J}$ and CD45.1Foxp ${ }^{\mathrm{GFP}}$-C57BL6/J mice were kindly provided by Lucienne Chatenoud (Institut Necker Enfants Malades, INSERM U1151, Paris, France). All mice were bred and housed in a specific pathogen-free facility in microisolator cages and used at 8-12 weeks of age in protocols approved by the local Ethical Committee (CEEA34.0AP.018.11).

\section{Recovery of mobMPP cells}

C57BL6/J mice (B6) were injected subcutaneously for 5 consecutive days with recombinant human G-CSF $(200 \mu \mathrm{g} / \mathrm{kg} /$ day) (Neupogen, Amgen, France) and recombinant murine Flt3$\mathrm{L}(20 \mu \mathrm{g} / \mathrm{kg} /$ day) (Immunotools, Friesoythe, Germany). At day 6 , spleen cells labeled with $\mathrm{mAbs}$ directed against mature lineage markers (CD4, CD8, Gr-1, CD45R, Ter119, CD11b) were depleted with anti-rat Ig-coated magnetic beads (Invitrogen Dynal, ThermoFisher Scientific, Cergy Pontoise, France). The lineage negative $\left(\operatorname{lin}^{-}\right)$fraction was electronically sorted, as previously described (7). Briefly, mobMPP were stained with appropriately labeled mAbs: CD34, CD117, Sca-1, CD11b (eBioscience), after incubation with purified anti-CD16/32mAbs to block non-specific $\mathrm{FcR}$ binding and electronically sorted as $\mathrm{CD} 117^{+} \mathrm{Sca}-1^{+} \mathrm{CD} 34^{+} \mathrm{CD} 11 \mathrm{~b}^{-/ \text {low }}$ cells.

Human peripheral blood samples (10 ml EDTA-tube) from rhG-CSF-treated (filgastrim $10 \mu \mathrm{g} / \mathrm{kg} /$ day for 5 consecutive days) healthy allogeneic donors (randomly selected at Necker Hospital and Saint Antoine Hospital in Paris) were collected after informed consent. Ficoll-purified peripheral PBMC were stained with the following antibodies: CD34, CD38, CD45RA, CD90 (eBioscience, Life Technologies, Villebon-sur-Yvette, France) and sorted (FACS Aria II, BD Bioscience, Le Pont de Claix, France) as $\mathrm{CD} 34^{+} \mathrm{CD} 38^{+} \mathrm{CD} 90^{-} \mathrm{CD} 45 \mathrm{RA}^{-}$mobilized MPP cells, and mobilized hematopoietic stem cells (mobHSC) identified by their $\mathrm{CD} 34^{+} \mathrm{CD} 38^{-} \mathrm{CD} 90^{+} \mathrm{CD} 45 \mathrm{RA}^{-}$phenotype.

\section{Proliferation Assays}

In mice, conventional $\mathrm{T}$ cells from $\mathrm{B} 6$ mice were purified by negative selection using a CD4 T cell depletion kit (Miltenyi Biotec, BergischGladbach, Germany). Purity was routinely above $98 \%$. Natural Tregs were stained with appropriately labeled $\mathrm{mAbs}$ against CD4 and $\mathrm{CD} 25$ and electronically sorted as $\mathrm{CD} 4^{+} \mathrm{CD} 25^{\text {high }}$.

$\mathrm{T}$ cell activation (including conventional $\mathrm{CD} 4^{+} \mathrm{T}$ cells, conventional $\mathrm{CD}^{+} \mathrm{CD} 25^{-} \mathrm{T}$ cells and natural $\mathrm{CD} 4^{+} \mathrm{CD} 25^{\text {high }}$ Tregs) was performed with allogeneic dendritic cells or, alternatively by non-specific TCR activation, with anti-CD3 and $\mathrm{CD} 28$ antibodies. Mature dendritic cells were harvested from the spleen of $\mathrm{BALB} / \mathrm{cJ}$ (or $\mathrm{C} 3 \mathrm{H} / \mathrm{HeJ}$ ) mice with a pan-DC selection kit (Miltenyi Biotec). B6 $\mathrm{T}$ cells were stained with $5 \mu \mathrm{M}$ carboxyfluorescein succinimidyl ester (CFSE) (Invitrogen, Life Technologies, Villebon-sur-Yvette, France). In Mixed Lymphocyte Reaction (MLR), B6 T cells were mixed with DC stimulators at a ratio of five $\mathrm{T}$ cells for one $\mathrm{DC}$, and plated in a 96well round bottom culture plate $\left(5.10^{4} \mathrm{~T}\right.$ cells/well). In some experiments, mobMPP were added at $5.10^{4} /$ well (1:1 $\mathrm{T}$ cell ratio), $10.10^{4} /$ well ( $2: 1 \mathrm{~T}$ cell ratio) or $15.10^{4} /$ well ( $3: 1 \mathrm{~T}$ cell ratio). In some experiments, Tregs were added at 5.10 $/$ well (1:1 T cell ratio) alone or with mobMPP at a 1:1:1 T cell ratio. Non-specific Treg activation was performed in a 96 round bottom plate coated with $10 \mu \mathrm{g} / \mathrm{ml}$ anti-CD3 $\mathrm{mAb}$ (clone 2C11) and $10 \mu \mathrm{g} / \mathrm{ml}$ anti-CD28 $\mathrm{mAb}$ (Biolegend) for $2 \mathrm{~h}$ before the addition of T cells (50,000/well). In some experiments, monoclonal IL-2 blocking antibody was used at $10 \mu \mathrm{g} / \mathrm{ml}$ (R\&D Systems). Cells were incubated in custom RPMI 1640 medium supplemented with $10 \%$ fetal calf serum, $50 \mu \mathrm{M} 2$ mercaptoethanol and $100 \mathrm{U} / \mathrm{ml}$ penicillin-streptomycin (Life Technologies, Villebon-sur-Yvette, France). 
Conventional human $\mathrm{T}$ cells were purified by negative selection using a pan $\mathrm{T}$ cell depletion kit (Miltenyi Biotec). Purity was routinely above $98 \%$. Human naïve Tregs were sorted (FACS Aria II, BD Bioscience, le Pont de Claix, France) as $\mathrm{CD}^{+} \mathrm{CD} 4^{+} \mathrm{CD} 25^{+} \mathrm{CD} 45 \mathrm{RA}^{+}$cells and conventional $\mathrm{T}$ cells were sorted ad $\mathrm{CD} 3^{+} \mathrm{CD} 4^{+} \mathrm{CD} 25^{-} \mathrm{T}$. They were plated at 50,000 cells/well in round-bottom 96-well microculture plates with or without mobMPP at a 1:1 T cell ratio in a final volume of $200 \mu \mathrm{l}$. Non-specific T cell activation was induced with $10 \mu \mathrm{g} / \mathrm{ml}$ anti-CD3 $\mathrm{mAb}$ (clone UCHT1, R\&D Systems) and $10 \mu \mathrm{g} / \mathrm{ml}$ anti-CD28 mAb (clone 37407, R\&D systems) for $2 \mathrm{~h}$ before adding T cells $(50,000 /$ well). In some experiments, monoclonal IL-1 $\beta$ blocking antibody was used (mouse anti-human clone 2805, R\&D Systems).

\section{Flow Cytometry}

In vivo, for some experiments, allo-HSCT was performed with $\mathrm{T}$ cells from congenic CD45.1-Foxp ${ }^{\mathrm{GFP}} \mathrm{B} 6$ mice. Thereafter, donor natural Tregs were analyzed at days 8 and 30 post-transplantation, in lymph nodes and spleen using mAbs against CD45.1, CD3, CD4, CD25 (eBioscience).

In vitro, cultured Tregs were characterized with anti-CD4 and anti-CD25 (eBioscience). Foxp3 was measured following surface staining with fixation/permeabilization working solution according to the manufacturer's guidelines (eBioscience). Intracellular IL-2 cytokine (eBioscience) staining was performed after a 3-h incubation of cultured Tregs +/- mobMPP with PMA $(10 \mathrm{ng} / \mathrm{ml})$ plus ionomycin $(500 \mathrm{ng} / \mathrm{ml})$ and Brefeldin A $(2 \mathrm{mg} / \mathrm{ml})$ at $37^{\circ} \mathrm{C}$ and $5 \% \mathrm{CO}_{2}$.

In human healthy donors, mobMPP were stained with appropriately labeled mAbs against CD34, CD38, CD45RA, CD90, CD13 and CD33 (eBioscience). Tregs were labeled with anti- CD3, -CD4, -CD25 and -CD45RA, (eBioscience). To confirm that naïve Tregs were all Foxp $3^{+}$, sorted naïve Tregs $\mathrm{CD}^{+} \mathrm{CD}^{+} \mathrm{CD} 25^{+} \mathrm{CD} 45 \mathrm{RA}^{+}$were fixed/permeabilized (Fix/Perm solution, eBioscience) and stained according to the manufacturer's instructions (eBioscience). For flow cytometric characterization of freshly sorted mobMPP, intra-cellular cytokine (IL-1 $\beta$ ) staining was performed after 3 - $\mathrm{h}$ incubation with brefeldin A $(2 \mathrm{mg} / \mathrm{ml})$. Flow cytometric characterization of Tregs $+/-$ mobMPP after 4 days of culture, intracellular cytokine (IL-2, IFN- $\gamma$ and TNF- $\alpha$, eBioscience) staining was performed after 3-h incubation with PMA (10 ng/ml) and ionomycin $(500 \mathrm{ng} / \mathrm{ml})$ and brefeldin $\mathrm{A}(2 \mathrm{mg} / \mathrm{ml})$ at $37^{\circ} \mathrm{C}$ and $5 \% \mathrm{CO}_{2}$. Samples were analyzed on a FACS Canto II cytometer (BD Biosciences) using FlowJo software (Treestar, Ashland, OR).

\section{Acute GVHD}

$\mathrm{BALB} / \mathrm{cJ}$ recipients were lethally irradiated using $600 \mathrm{cGy}$ total body X-ray irradiation on day -1 followed by intravenous caudal vein infusion of $10^{7} \mathrm{~T}$ cell-depleted $\mathrm{B} 6$ donor bone marrow (BM) cells, $2 \times 10^{6}$ purified B6 T cells, with or without $0.35 \times 10^{6} \mathrm{~B} 6$ mobMPP on day 0 . Control groups were transplanted with BM cells alone (syngenic group) or BM $+\mathrm{T}$ cells (control T cell group). For some experiments, $2 \times 10^{6}$ purified CD45.1-Foxp3 ${ }^{\mathrm{GFP}}$-B6 T cells were used for allo-HSCT to analyze donor Tregs on day- 8 and day-30 post-HSCT by flow cytometry. In other experiments, allo-HSCT was carried out with $0.35 \times 10^{6}$ CD45.1B6 mobMPP and $2 \times 10^{6}$ purified CD45.2-Foxp3 ${ }^{\text {GFP }}$-B6 $\mathrm{T}$ cells to evaluate donor mobMPP in lymph nodes and spleen at day-15 post-HSCT by confocal microscopy. AlloHSCT was performed with donor cells lacking Tregs, using BALB/cJ recipients having received a lethal 600 cGy total X-ray body irradiation on day- -1 followed by intravenous injection into the caudal vein of $10^{7} \mathrm{~T}$ cell-depleted B6 donor bone marrow (BM) cells, $2 \times 10^{6}$ purified B6 CD25 $5^{-} \mathrm{T}$ cells (control CD25 ${ }^{-} \mathrm{T}$ cells group), and $+/-0.35 \times 10^{6} \mathrm{~B} 6$ mobMPP on day- 0 . All recipient mice were monitored daily for survival, and at least twice a week for weight and acute GVHD score. The clinical scoring system was based on six parameters as previously described (2): weight loss, posture, activity, fur texture, skin integrity, and diarrhea. A severity scale of $0-2$ was used for each parameter, with a maximum global score of 12 .

\section{Confocal Microscopy Analysis of Recipient Lymph Nodes and Spleens}

Spleens and lymph nodes from allografted BALB/c j mice were harvested on day 15 and immediately embedded in OCT (Sakura), snap frozen in liquid nitrogen, and stored at $-80^{\circ} \mathrm{C}$. Cryosections $(7-9 \mu \mathrm{m})$ were cut, fixed in cold $\left(-20^{\circ} \mathrm{C}\right)$ acetone for $10 \mathrm{~min}$, rehydrated in washing buffer (TBS, $\mathrm{pH} 7.6$ ), and exposed to blocking buffer $(0.5 \%$ BSA and $10 \%$ goat serum in PBS) for $30 \mathrm{~min}$ at room temperature. Sections were then treated for $60 \mathrm{~min}$ at room temperature with rat anti-mouse $\mathrm{CD} 3$ and mouse biotin anti-CD45.1 antibody (eBioscience). Controls were set up without primary antibodies. Sections were washed 3-4 times, incubated with the secondary antibody followed by conjugated streptavidin-CY5 (20 $\mathrm{min}$ at room temperature). Sections were washed and mounted in Fluoromont-G (Southern Biotech). Images were acquired by confocal microscopy with a LSM 700 (Zeiss). Fluorescence of single channels was measured, and control reference was systematically done. Pictures were taken at $40 \times$ magnification. Images were analyzed and processed with Image J version 1.46 .

\section{Statistical Analysis}

The results were averaged in each group. Statistical analyses were performed using GraphPad Prism software version 8, and data are presented as mean \pm SEM. Before analysis, the normality assumption was examined. Comparisons were performed by one-way ANOVA with Tukey's multiple comparison when comparing more than two groups with normal distribution of values, by unpaired $t$-test for comparing two groups with normal distribution of values. Survival curves were compared by logrank test. A $p$-value $<0.05$ was considered statistically significant.

\section{RESULTS}

\section{MobMPP Inhibit Alloreactive T Cell Proliferation by Expanding Alloreactive Tregs in Mice}

We evaluated the effect of splenic mobMPP on alloreactive T cell proliferation induced by allogeneic dendritic cells during mixed lymphocyte reaction (MLR). We failed to observe a significant immunosuppression when either $\mathrm{CD} 4^{+} \mathrm{CD} 25^{-} \mathrm{T}$ cells (Figure 1A) or total $\mathrm{CD}^{+}$(including $\mathrm{CD} 25^{+}$and $\mathrm{CD} 25^{-}$) $\mathrm{T}$ cells (Figure 1B) 
were used, even if mobMPP were added at higher ratios (Figure 1C). By contrast, mobMPP became strongly immunosuppressant on alloreactive $\mathrm{T}$ cell proliferation when cultured with Tregs at a 1:1:1 ratio (Figure 1D). In fact, we observed that Tregs activated by allogeneic dendritic cells or alternatively by anti-CD3 and -CD28 antibodies, were expanded in terms of cell counts and proportion of divided cells, assessed by CFSE dilution, from day-4 of cocultures (Figure 1E). To ensure that expanding Treg cells maintain their phenotype, we studied activated Tregs (+/- mobMPP) after 4 days of culture. We observed that Tregs maintained their $\mathrm{CD} 4{ }^{+} \mathrm{CD} 25^{\text {high }}$ Foxp $^{+}$phenotype (Supplementary Data, Figure S1A) and did not produce IL-2 in contrast with activated conventional $\mathrm{T}$ cells (Supplementary Data, Figure S1B). Notably, we observed that mobMPP did not produce IL-2 either (Figure S1B). In addition, Treg expansion by mobMPP occurred even in the presence of neutralizing anti-IL-2 antibody, demonstrating that mobMPP promoted Treg expansion by an IL-2 independent mechanism (Supplementary Data, Figure S1C).

\section{Adoptively Transferred mobMPP Prevent Acute GVHD and Improve Donor Treg Expansion}

We further investigated how mobMPP affected allogeneic HSCT in a murine model. Donor cells were electronically sorted as $\operatorname{lin}^{-}$, $\mathrm{CD}_{117^{+}}, \mathrm{Sca}^{-}{ }^{+} \mathrm{CD} 34^{+}, \mathrm{CD} 11 \mathrm{~b}^{-}$cells from the spleen of $\mathrm{B} 6$ mice having received G-CSF and Flt3-L injections (mobMPP). $\mathrm{BALB} / \mathrm{c}$ mice allografted with $2.10^{6} \mathrm{~T}$ cells together with mobMPP showed a significantly improved survival, as compared to allogeneic controls without mobMPP (Figure 2A). This group of recipients was protected against GVHD and weight loss (Figure 2B). Mice allografted with $2.10^{6} \mathrm{CD} 25^{-} \mathrm{T}$ cells (devoid of Tregs) together with mobMPP did not survive significantly
A

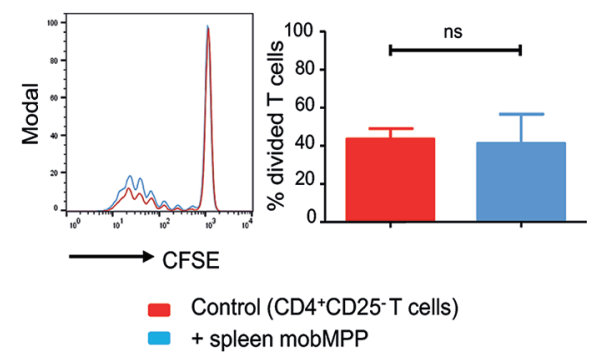

D

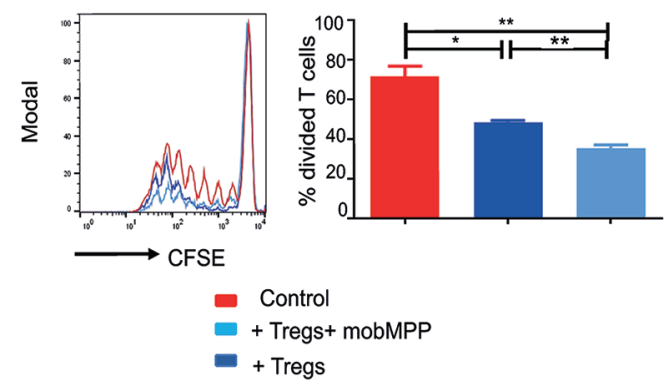

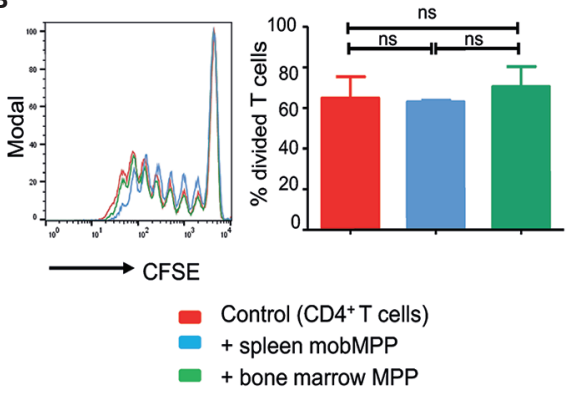

C

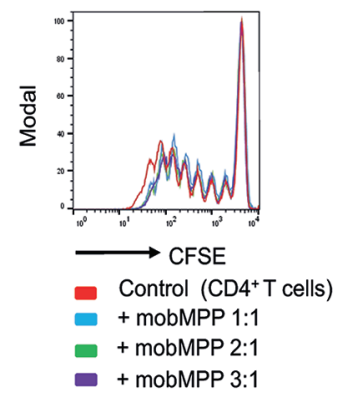

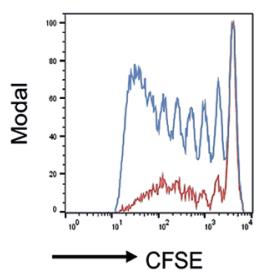

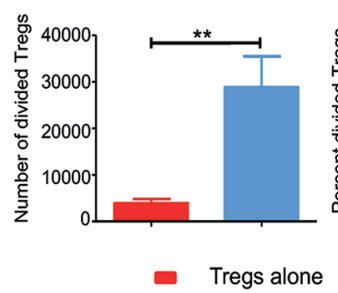

- Tregs + mobMPP

FIGURE 1 | G-CSF-mobilized MPP can suppress MLR by enhancing Foxp3 ${ }^{+}$Treg proliferation. (A) CFSE dilution was assessed in B6 CD4 ${ }^{+}$CD25- T cell (50,000/well) activated by BALB/c DC (10,000/well) cultured alone (red) or with splenic mobMPP (blue) at a 1:1 ratio $\left(50,000 \mathrm{CD} 4^{+} \mathrm{CD} 25^{-} \mathrm{T}: 50,000\right.$ mobMPP/well). Percentage of divided T cells were $43.5 \pm 3.17 \%$ in control, versus $41.23 \pm 8.9 \%$ in coculture with mobMPP $(p=0.80)$. Data from 3 independent experiments $(n=3)$ were compared using Student's unpaired $t$-test (ns, not significant). (B) Total B6 CD4 ${ }^{+} \mathrm{T}$ cells (containing both CD25- and CD25 $5^{+} \mathrm{CD} 4^{+} \mathrm{T}$-cells) activated by BALB/c dendritic cells were cultured alone (red), with splenic mobilized MPP at a 1:1 ratio (light blue), or with non-mobilized bone marrow MPP at a 1:1 ratio (green). Percentages of divided T cells were $64.88 \pm 10.48 \%$ in control, versus $63 \pm 1.30 \%$ and $70.43 \pm 17.19 \%$ in coculture with mobMPP $(p=0.87)$ or bone marrow MPP $(p=0.73)$, respectively. Data were compared using one-way ANOVA with Tukey's multiple comparison test (ns, not significant). (C) Total B6 CD4 ${ }^{+} \mathrm{T}$ cells (containing both CD25- and CD25 ${ }^{+}$ $\mathrm{CD4}^{+} \mathrm{T}$-cells) CFSE dilution is similar when B6 CD4 ${ }^{+} \mathrm{T}$ cells activated by BALB/c DC were cultured alone or with mobMPP at 1:1 ratio $\left(50,000 \mathrm{CD} 4^{+} \mathrm{T}\right.$ cells:50,000 mobMPP/well). A higher number of MobMPP in the well (1:2 ratio (50,000 CD4 $4^{+} \mathrm{T}$ cells: 100,000 mobMPP/well), or 1:3 ratio (50,000 CD4 ${ }^{+}$T cells: 150,000 mobMPP/ well) does not impact total B6 CD4 ${ }^{+} T$ cell proliferation (one experiment, $n=1$ ). (D) B6 $C D 4^{+} C D 25^{-} C D 45.1 T$ cells activated by BALB/c DC were cultured alone (red) or with CD45.2 Tregs at a 1:1 ratio (dark blue), or with CD45.2 Tregs and CD45.2 mob-MPP at a 1:1:1 ratio (light blue) $(n=3)$. Percentages of CD45.1 divided T cells were respectively $71.54 \pm 5.27 \%$ in control, $48.52 \pm 0.86 \%$ in the presence of Tregs, $\left(p=0.0125\right.$, *) and $35.49 \pm 1.66 \%$ with both Tregs and mobMPP, $\left({ }^{* \star} p=0.0028\right)$. The percentage of divided T cells was higher when both Tregs and mobMPP were present, rather than Tregs alone $\left.{ }^{* *} p=0.0023\right)$. Data were compared using Student's unpaired $t$-test (ns, not significant). (E) B6 Treg cells activated with allogeneic BALB/c DC were cultured alone (red) or with mobMPP (blue) ( $n=11)$. The number of Tregs in proliferation ( $\geq$ division 1) is lower when Tregs are cultured alone (3918 \pm 905 vs. $\left.28792 \pm 6659,{ }^{* *} p=0.0014\right)$. Percentages of Tregs in proliferation ( $\geq$ division 1) are also lower when Tregs are cultured alone (64.28 $\pm 25.66 \%$ vs. $87.40 \pm 9.26 \%,{ }^{*} p=0.0108$, using Student's unpaired $t$-test). 
longer than allogeneic controls without mobMPP (Figure 2C), underlining the strict requirement for Tregs for the protective effect of mobMPP. Eight days after allo-HSCT, we found that mesenteric and inguinal lymph nodes contained an increased percentage of Tregs among the donor CD45.1 $\mathrm{CD} 4^{+}$population, by contrast with spleen. This percentage could reach $42 \%$ one month after allo-HSCT in surviving recipients (Figure 2D). This accumulation of Tregs in recipient inguinal lymph nodes was confirmed by confocal microscopy, which revealed also that mobilized MPP and expanded Tregs were in close contact with each other (Figure 2E).

\section{Adoptive Transfer of mobMPP Modulates Alloreactive T Cell Proliferation In Vivo}

We further assessed whether in vivo expanded Tregs exhibited specific alloreactive immunosuppressive functions. For this purpose, we performed MLR with 50,000 CD25 ${ }^{-}$B6 T cells/well. At day-8 post-transplantation, Tregs expanded from B6 CD45.1 donor cells in $\mathrm{BALB} / \mathrm{c}$ recipients in the presence or absence of mobMPP were electronically sorted and added during MLR, at a very low ratio (10 $\mathrm{T}$ cell: $1 \mathrm{Treg}$ ). We observed that in vivo expanded Tregs could totally suppress MLR when B6 T cells were activated not only by BALB/c but also by $\mathrm{C} 3 \mathrm{H}$ DC, demonstrating that in vivo expanded Tregs were highly suppressive and capable of hampering alloreactive responses nonspecifically (Figure 3A). We further tested $\mathrm{CD} 45.1^{+} \mathrm{CD} 4^{+} \mathrm{CD} 25^{\text {low }}$ allografted T cells, on day 8 after transplantation. During MLR, only $\mathrm{CD} 4^{+} \mathrm{CD} 25^{\text {low }} \mathrm{T}$ cells sorted from BALB/c mice transplanted with mobMPP exhibited a significantly reduced proliferation after stimulation by $\mathrm{BALB} / \mathrm{c}$ DC, compared with proliferation of $\mathrm{CD} 4^{+} \mathrm{CD} 25^{\text {low }} \mathrm{T}$ cells from allografted mice that had not received mobMPP. However, this suppression did not occur in the presence
A

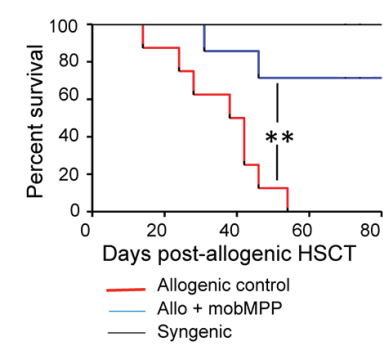

D

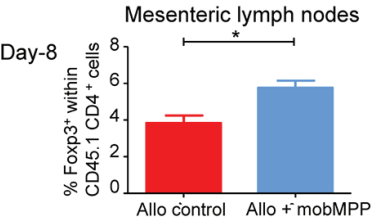

B

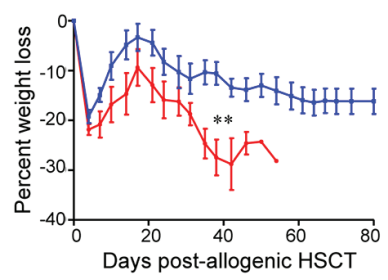

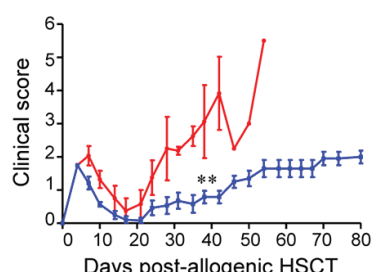

Days post-allogenic HSCT

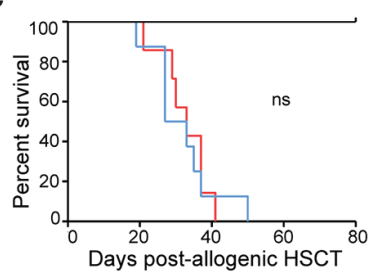

CD25- T cells

- CD25-T cells + mobMPP
Syngenic

$\rightarrow$ Allogeneic contro $\rightarrow$ Allo + mobMPP

Inguinal lymph nodes

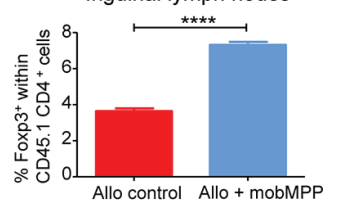

E

FOX P3-GFP

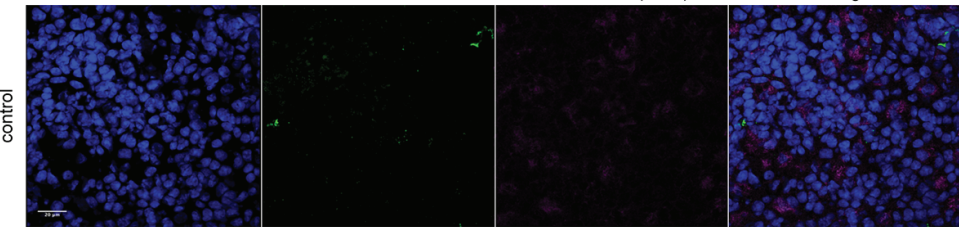

Day-30
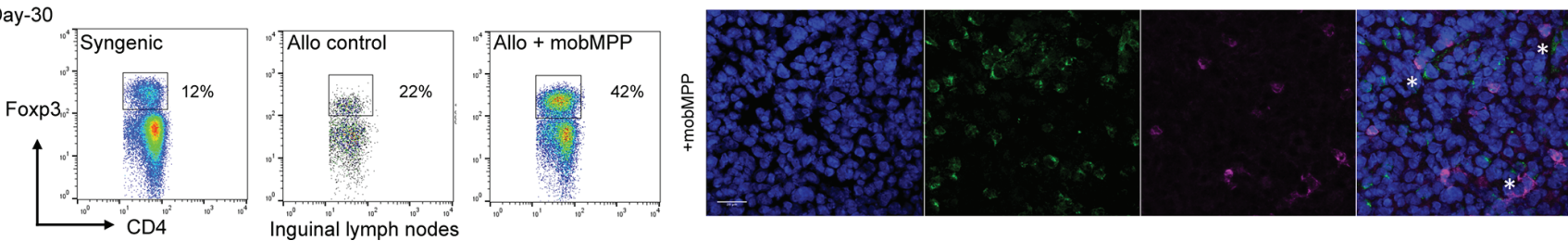

FIGURE 2 | G-CSF mobilized MPP prevent GVHD by enhancing Foxp3 ${ }^{+}$Tregs in vivo. (A) Lethally irradiated (6 Gy) BALB/cJ recipients received $1 \times 10^{7}$ B6 T celldepleted BM cells alone (black, $n=4$ ) or together with $2 \times 10^{6}$ purified B6 T cells (allogeneic control, red, $n=7$ ). In a third group $0.35 \times 10^{6}$ B6-derived mobMPP were co-transferred with the two other populations (blue, $n=7$ ) on day 0 . Less than $40 \%$ of mice having received co-transferred mobMPP died over 80 days whereas median survival was 40 days without mobMPP $\left(^{* *} p=0.004\right)$. Data shown represent pooled results from 2 independent experiments. Results were compared with Kaplan-Meier survival curves. (B) Mean weight loss of BALB/cJ recipients at day 40 post-HSCT (median survival group) was: $-10.57 \pm 2.28 \%$ in mice co-injected with mobMPP $(n=6)$ vs. $-27.44 \% \pm 3.60 \%$ in allogeneic controls $(n=4)$. Mean clinical GVHD scores in recipients at day 40 post-HSCT was: $0.8 \pm 0.19$ in mice co-injected with mobMPP $(n=$ 6) vs. $3.06 \pm 1.1$ in allogeneic controls $(n=4)$. Data were compared using Student's unpaired $t$-test $\left({ }^{* *} p \leq 0.01\right)$. (C) Lethally irradiated $(6$ Gy) BALB/cJ recipients received $1 \times 10^{7}$ B6 T-cell depleted BM cells alone (black, $n=4$ ), with $2 \times 10^{6}$ purified CD25- B6 T cells (allogeneic control, red, $n=7$ ) or with additional $2 \times 10^{6}$ purified CD25 B6 T cells and $0.35 \times 10^{6}$ B6-derived mobMPP (blue, $n=7$ ). Median survival in mice having received allogeneic HSCT plus CD25 $5^{-}$cells was 30 days vs. 33 days in mice with co-transferred mobMPP $(p=0.52)$. Results were compared with Kaplan-Meier survival curves (ns, not significant). (D) Percentage of Foxp $3^{+}$Tregs in allogeneic CD45. $1^{+} \mathrm{CD}^{+}{ }^{+} \mathrm{B} 6 \mathrm{~T}$ cells were studied in control BALB/c mice (red) or in BALB/c mice transplanted with mobMPP (blue) ( $\mathrm{n}=3$ ). The percentage of Tregs in the CD45. $1^{+} \mathrm{CD} 4^{+} \mathrm{T}$ cells in mesenteric lymph nodes were $3.84 \pm 0.71 \%$ vs. $5.76 \pm 0.67 \%,\left({ }^{*} p=0.0274\right)$, respectively. The percentage of Tregs in the CD45. $1^{+} \mathrm{CD} 4^{+} \mathrm{T}$ cells in inguinal lymph nodes were $3.64 \pm 0.28$ vs. $7.31 \pm 0.29 \%$, ( ${ }^{\star \star \star \star} p<0.0001$, using Student's unpaired t-test). (E) Representative confocal fluorescence micrograph of inguinal lymph nodes. BALB/c mice were sacrificed at day 15 post-allogeneic HSC and inguinal lymph nodes were harvested for confocal microscopy. Top: inguinal lymph node from control allografted BALB/c mice. Below: inguinal lymph node from allografted BALB/c mice with CD45.1 mobMPP (DAPI, blue; Foxp3, green; CD45.1 red; merged images show Foxp3/CD45.1 colocalization, indicated by *). Bar: $0.2 \mu \mathrm{m}$. 
of $\mathrm{C} 3 \mathrm{H}$ DC, suggesting that natural Tregs already suppressed alloreactive $\mathrm{CD} 25^{\text {low }} \mathrm{T}$ cells from day- 8 post-transplantation onwards (Figure 3B). Therefore, mobilized MPP have contributed to expand highly suppressive donor natural Tregs that immediately suppressed alloreactive $\mathrm{T}$ cells in BALB/c recipients. It can therefore be concluded that in vivo Treg expansion by mobMPP confers allo-antigen specific $\mathrm{T}$ cell suppression to control GVHD in allo-HSCT.

\section{Characterization of a Human mobMPP Counterpart Mobilized by G-CSF}

We analyzed the CD $34^{+}$fraction of PBSC from 30 healthy donors. It has been previously reported that human HSC are enriched in the $\mathrm{Lin}^{-} \mathrm{CD} 34^{+} \mathrm{CD} 38^{-} \mathrm{CD} 90^{+}$cell compartment of non-mobilized cord blood and bone marrow cells. By contrast, in mobilized PBSCs, the majority of the $\mathrm{CD}_{3} 4^{+}$cells are $\mathrm{CD} 38^{+} \mathrm{CD} 90^{-}$ $\mathrm{CD}_{45 \mathrm{RA}^{-}}$and homogeneously expressed low levels of CD13 and CD33 (Figure 4A). We distinguished mobMPP as $\mathrm{CD}_{4} 4^{+} \mathrm{CD} 38^{-} \mathrm{CD}^{-} 0^{-} \mathrm{CD} 45 \mathrm{RA}^{-}$and mobilized hematopoietic stem cells (mobHSC) as $\mathrm{CD} 34^{+} \mathrm{CD} 38^{-} \mathrm{CD} 90^{+} \mathrm{CD} 45 \mathrm{RA}^{-}$. We tested these two main subsets in co-culture with naïve Tregs (described in Figure 4A). Only the $\mathrm{CD} 34^{+} \mathrm{CD} 38^{+} \mathrm{CD} 90^{-}$ $\mathrm{CD}_{45 \mathrm{RA}^{-}}$subset (mobMPP) could increase naïve Treg proliferation (Figure 4B). MobMPP did not affect conventional $\left(\mathrm{CD} 4^{+} \mathrm{CD} 25^{-}\right) \mathrm{T}$ cell proliferation (Figure $\left.4 \mathrm{C}\right)$. After four days of culture, naïve Treg cells were still Foxp $3^{+}$(Figure 4D). To further investigate how mobMPP could enhance naïve Treg proliferation, we first prevented cell-to-cell contact in transwell cultures. We observed that naive Treg proliferation, induced by mobMPP, was not totally abolished in transwell cultures (Supplementary Data, Figure S2A). However, neither naïve Treg cells nor mobMPP were able to produce IL-2, TNF- $\alpha$, and IFN- $\gamma$, the main cytokines involved in $\mathrm{T}$ cell proliferation (Supplementary Data, Figure S2B). Taking into account a previously suggested mechanism in mice (9), and higher IL- $1 \beta$ production reported in $\mathrm{CD} 34^{+}$cells from PBSC relative to steady state bone marrow cells (10), we observed that $5 \%$ of freshly sorted mobMPP produce IL-1 $\beta$ (Supplementary Data, Figure S2C). When neutralizing IL-1 $\beta$ by an IL-1 $\beta$ blocking antibody, naïve Treg survival and proliferation were reduced, although not fully abolished (Supplementary Data, Figure S2D).

\section{DISCUSSION}

Acute and chronic graft-versus-host diseases (GVHD) are major causes of morbidity and mortality after allo-HSCT. In mice, reduced frequency of Tregs contributes to both of these disorders (11). In humans, the incidence of natural Treg in peripheral blood $(\mathrm{PB})$ is very low, amounting only to $1-2 \%(12)$, which is probably an overestimation because of contaminating $\mathrm{CD} 25^{+} \mathrm{T}$ effector cells (13). This percentage is inversely correlated with the
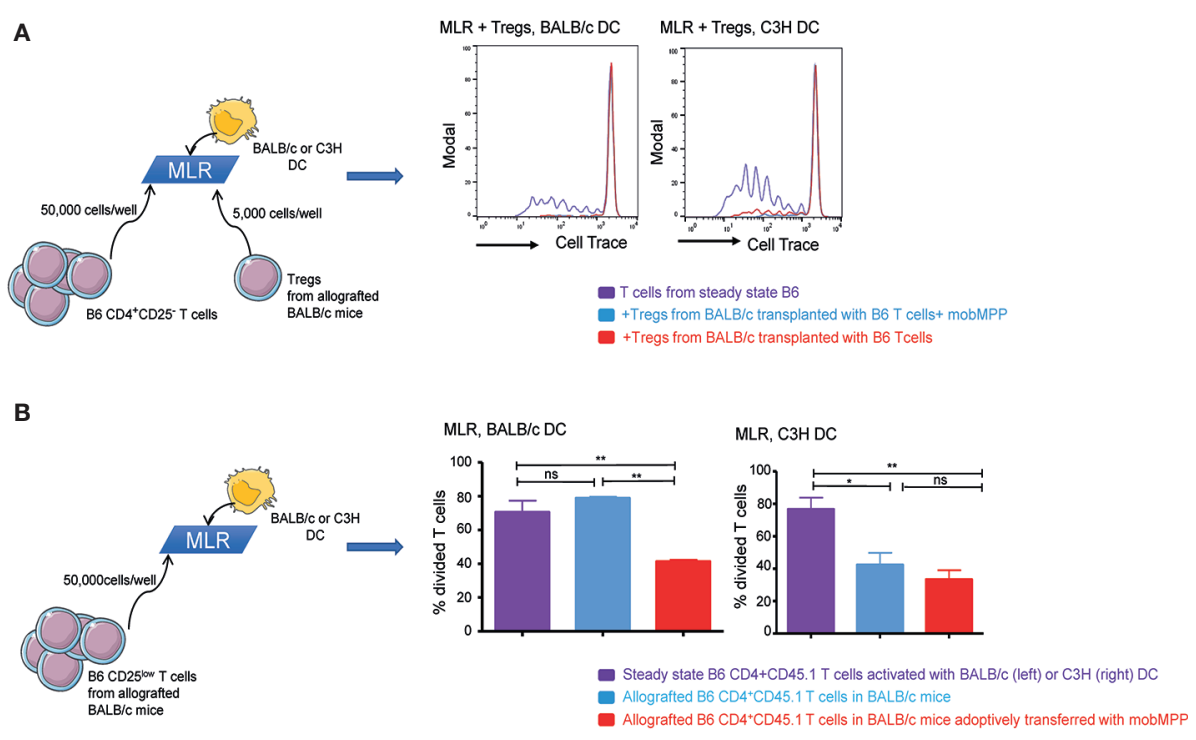

FIGURE 3 | G-CSF mobilized MPP induce tolerance. (A) Steady state B6 CD4 ${ }^{+}$CD $45.1^{+}$T cells activated by BALB/c (left) or C3H (right) DC were cultured alone (purple) or with Tregs in 10:1 ratio (50,000 T cells: 5,000 Tregs). Tregs were sorted from the spleen of allografted control BALB/c mice (red), or from allografted BALB/c mice with mobMPP (light blue) $(n=3)$. CFSE dilution within CD45.1 $1^{+} T$ cells were compared. (One representative experiment out of 3). (B) Left: Steady state B6 CD4 ${ }^{+} \mathrm{CD} 25^{\text {low }} \mathrm{CD} 45.1^{+} \mathrm{T}$ cells activated by BALB/C DC were analyzed for CFSE dilution (purple) and compared to CFSE dilution of allografted B6 $\mathrm{CD} 4^{+} \mathrm{CD} 25^{\text {low }} \mathrm{CD} 45.1^{+} \mathrm{T}$ cells in BALB/c mice with (light blue) or without (red) adoptive transfer of mobMPP. Percentage of steady state B6 CD4 ${ }^{+} \mathrm{CD} 25^{\text {low }} \mathrm{CD} 45.1^{+} \mathrm{T}$ cells in division is $70.57 \pm 6.81 \%$ (purple) vs. $41.37 \pm 1.03 \%$ (red), vs. $70.57 \pm 6.81 \%$ (light blue), respectively ${ }^{* *} p \leq 0.005$ by one-way ANOVA with Tukey's multiple comparisons test. Right: Steady state B6 CD4 ${ }^{+} \mathrm{CD} 25^{\text {low }} \mathrm{CD} 45.1^{+} \mathrm{T}$ cells activated by $\mathrm{C} 3 \mathrm{H}$ dendritic cells were analyzed for CFSE dilution (purple) and compared to CFSE dilution of allografted B6 CD4 ${ }^{+} \mathrm{CD} 25^{\text {low }} \mathrm{CD} 45.1^{+} \mathrm{T}$ cells in $\mathrm{C} 3 \mathrm{H}$ mice with (light blue) or without (red) adoptive transfer of mobMPP. Percentage of steady state B6 CD4 ${ }^{+}$CD45.1 T cells in division is $76.60 \pm 7.18 \%$ (purple) vs. $42.40 \pm 7.35 \%$ (red), vs. $33.37 . \pm 5.69 \%$ (light blue), respectively, $\mathrm{n}=3,\left({ }^{*} p=0.0275,{ }^{\star \star} p=0.0097\right.$; ns, not significant, by one-way ANOVA with Tukey's multiple comparisons test). 
A
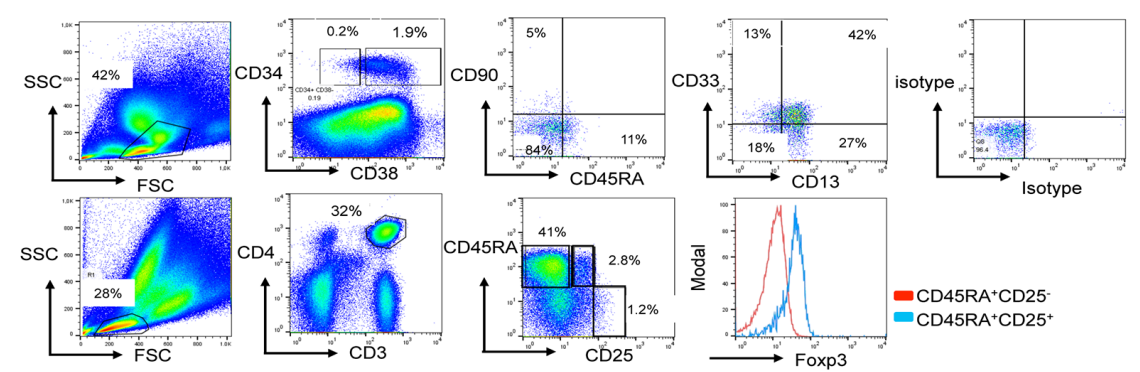

B

C
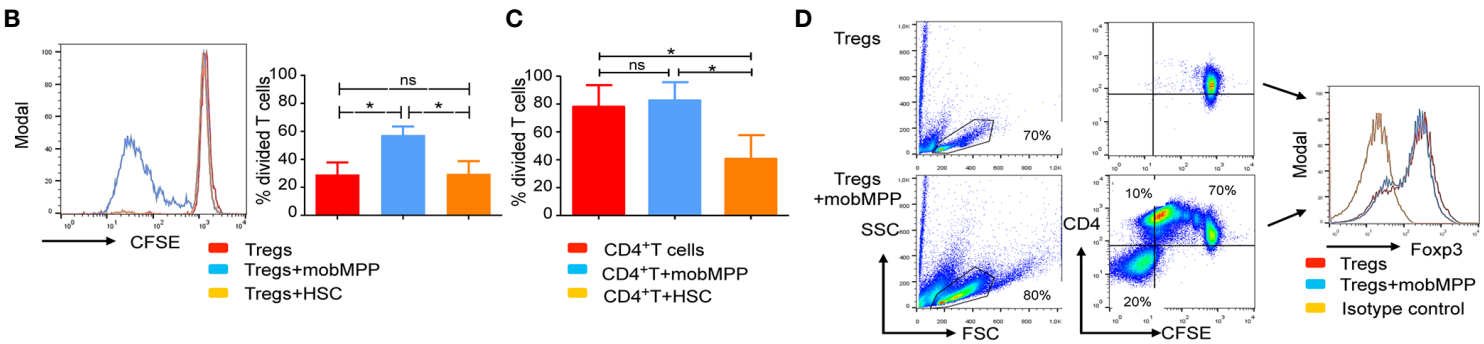

FIGURE 4 | Human mobilized MPP share features of immature myeloid cells endowed with naïve Treg proliferation properties. (A) Human G-CSF mobilized peripheral blood stem cells (PBSC) were analyzed by flow cytometry. We first distinguished the CD34+ fraction from the CD34 $4^{-}$fraction of cells. In the gated $\mathrm{CD}_{3}{ }^{+} \mathrm{CD} 34^{+}$fraction, a population of cells that lacked CD90 and CD45RA, homogeneously expressed CD13 and CD33 and was identified and termed mobMPP. Mobilized hematopoietic stem cells (mobHSC) were distinguished as CD $34^{+} \mathrm{CD} 38^{-} \mathrm{CD} 45 \mathrm{RA}^{-} \mathrm{CD} 90^{-}$. Below, in the same PBSC, naïve Tregs defined as $\mathrm{CD}^{+}{ }^{+} \mathrm{CD} 4^{+} \mathrm{CD} 45 \mathrm{RA} \mathrm{A}^{+} \mathrm{CD} 25^{+}$were analyzed by flow cytometry. All gates were based on isotype control. (B) Anti-CD3 and -CD28 activated naïve Treg cell proliferation after 4 days of culture alone (red) with mobMPP (light blue) or with mobHSC (orange) at a 1:1 ratio $(n=3)$. Percentages of divided naive Tregs were in control $=29.17 \pm 8.58 \%$ vs. $60.77 \pm 2.847 \%$ with mobMPP vs. $29.67 \pm 9.06 \%$ with mobHSC, respectively. Data were compared using one-way ANOVA with Tukey's multiple comparison test (ns, not significant, ${ }^{*} p=0.0371$ ). (C) Anti-CD3 and -CD28 activated CD4 ${ }^{+} \mathrm{CD} 25^{-} \mathrm{T}$ cell proliferation after 4 days of culture alone (red) with mobMPP (light blue) or with mobHSC (orange) at a 1:1 ratio $(n=3)$. Percentages of divided T cells were in control $=78.03 \pm 8.945 \mathrm{vs} .82 .57 \pm$ $7.583 \%$ with mobMPP, vs. $40.70 \pm 9.815 \%$ with mobHSC respectively. Data were compared using one-way ANOVA with Tukey's multiple comparison test (ns, not significant, ${ }^{*} p=0.0289$ ). (D) Naïve Treg cells activated by anti-CD3 and anti-CD28 were cultured alone or with mobMPP. After 4 days of culture, intra-nuclear Foxp3 was measured.

severity of acute (14) and chronic (14) GVHD. Among the strategies proposed to modulate and prevent GVHD, adoptive transfer of natural Tregs can reproducibly and efficiently prevent GVHD in murine models, but requires a high Treg dose (infusion of one Treg for one conventional donor T-cell) (15). Thus, in murine models, Treg expansion for adoptive transfer has been explored in a variety of approaches (16). In humans, cocultures with diverse antigen-presenting cells have been investigated, such as donor-derived stimulated B cells, that expand the pool of alloreactive Tregs present in the blood (17, 18), as well as DCs (19) and artificial APCs (20). However, depending on the state of activation of Tregs, their proliferative capacity remains highly variable $(21,22)$ and the procedure is time-consuming. Furthermore, ex vivo expansion of natural Tregs (nTregs) must be anticipated far ahead of allo-HSCT. The safety and efficacy of ex-vivo expanded nTreg infusions have been attested $(23,24)$ and confirmed with a trend toward a lower incidence of acute grade II-IV GVHD. Even though, the technical obstacles associated with direct Treg adoptive transfer would make an alternative strategy leading to an enhancement of donor Tregs in vivo following allo-HSCT preferable. Mobilized MPP are interesting candidates for such an approach. They are readily available during HSCT, since the hematopoietic stem cells used are increasingly recovered from peripheral blood after G-CSF mobilization. Our evidence for the capacity of G-CSFmobilized MPP to modulate autoimmunity (type 1 diabetes and EAE) through Foxp $3^{+}$Treg expansion and stabilization provides a further argument for their possible benefit during allo-HSCT. Starting from these findings, we explored whether their immunosuppressive functions applied also to allo-HSCT.

Our results show that mobMPP can selectively enhance survival and proliferation of activated Tregs in vitro, both in mice and humans. Their failure to promote proliferation of $\mathrm{CD} 25^{-}$cells may be considered an advantage over less selective options, such as IL-2 treatment (25), for which it is difficult to determine efficacious low doses, and foresee off-target effects, their short in vivo half-life being also problematic. Therefore, cellular therapy with mobilized MPP may provide a new method to expand in vivo alloantigen specific Tregs conferring protection against GVHD. Indeed, we observed that donor nTregs in mobMPP co-transferred recipients were rapidly expanded at allopriming sites and already exerted allospecific T-cell suppression at day-8 post-transplantation.

We observed that only mice given at least $0.35 .10^{6}$ mobMPP had significantly improved survival. In fact, cohorts receiving $0.1 .10^{6}$ mobMPP at the time of transplantation, did not significantly improve their survival (data not shown). The impact 
of higher mobMPP doses ( $>0.35 .10^{6} /$ mouse) on recipient outcomes was not studied. First, to avoid using excessive number of donor mice since one mobilized B6 mice was necessary to obtain $1.10^{5}$ mobMPP. Moreover, we assume that the dose of $3.5 .10^{5}$ mobMPP represents a relevant ratio for coinjection with $2.10^{6}$ $\mathrm{CD}^{+} \mathrm{T}$ cells containing approximately 1.4 to $1.8 .10^{5}$ natural Tregs in mice. Notably, the number of mobMPP required for protection in the allogeneic setting of GVHD is 10 to 30 -fold higher than in autoimmune settings where as few as 10,000 and 25,000 mobMPP were sufficient to provide protection against spontaneous type 1 diabetes $(7,8)$ and Experimental Autoimmune Encephalomyelitis (9), respectively. This difference may reflect the multiple target tissues in GVHD where mobMPP may have to migrate to and control the allogeneic response, in contrast with the tissue specificity characterizing the autoimmune experimental settings.

Tregs from GVHD patients exhibit multiple defects, including instability of Foxp3 expression, impaired suppressive functions, decreased migratory capacity and increased apoptosis (26). Since we demonstrated the stability of MobMPP-expanded Tregs at the molecular level (9), we assume that in vivo expanded nTregs are less prone to differentiate into effector $\mathrm{T}$ cells during the cytokine storm post-HSCT $(27,28)$, a differentiation reported in inflammatory responses (29). In the same manuscript, we demonstrated that mobilized MPPs increase the transcription factor t-Bet in Tregs which enables them to suppress pathogenic Th1 cells and induces the expression of chemokine receptors, particularly CXCR3, which condition the migration of cells toward Th1 inflamed GVHD target organs (30). Finally, we demonstrated that Treg expansion by mobilized MPPs was partly mediated through IL-1 $\beta$ in mice. In the present study we identified a human mobMPP counterpart sharing most likely a similar mechanism to promote Treg expansion. IL-1 $\beta$ has been previously reported as a mediator involved in the induction of Foxp $3^{+}$Tregs in response to CD $8 \alpha$ DCs exposed to GM-CSF (31). Moreover, these Tregs had a significantly higher ability to maintain Foxp3 expression when activated in the presence of IL$1 \beta$, which enhanced their capacity to suppress the effector $\mathrm{T}$ cell response in vitro and ongoing experimental autoimmune thyroiditis in vivo (32).

In humans the expression of inflammatory cytokine receptors IL-1R1 and TNFR2 has been described for being higher on resting mature Tregs than on naïve or memory $\mathrm{T}$ cells. While both receptors were upregulated upon activation through the $\mathrm{T}$ cell receptor (TCR), on all T cell subsets, IL-1R1 expression was maintained at significantly higher levels on activated Tregs than among other $\mathrm{T}$ cell subsets (33). Collectively, these results suggest that IL-1 $\beta$-IL-1R signaling between mobMPP and Tregs could be a potent and safe mechanism to enhance natural Tregs in vivo in mice and should be explored in humans. It is noteworthy that the effect of IL- $1 \beta$ on GVHD depends critically on the timing of its intervention during alloHSCT (34). Notably, in humans, IL-1 $\beta$ blockade during the period of initial $\mathrm{T}$-cell activation had no impact on the cumulative incidence of acute GVHD (35).

Altogether, our results support the notion that mobilized MPPs could become useful as a novel cellular therapy to expand functional alloantigen specific Tregs in vivo that may lead to a considerable improvement of allo-HSCT safety by preventing GVHD.

\section{DATA AVAILABILITY STATEMENT}

The original contributions presented in the study are included in the article/Supplementary Material. Further inquiries can be directed to the corresponding author.

\section{ETHICS STATEMENT}

The studies involving human participants were reviewed and approved by REG Allo NCTC02194868, CPP 24/04/2014, CCTIRS 18/06/2014, CNIL 17/04/2015. The patients/participants provided their written informed consent to participate in this study. The animal study was reviewed and approved by Paris Descartes University Ethical Committee and Ministry of Education and Research Ethical Committee (CEEA34.0AP.018.11).

\section{AUTHOR CONTRIBUTIONS}

MD'A and FZ designed the experiments, interpreted the data, and wrote the manuscript. MD'A, A-BN, VAA, AB, PG, MDC, and GF performed the experiments. MG-T provided technical support, and analyzed and interpreted the confocal microscopy. M-TR and $\mathrm{OH}$ provided the human HSC grafts. FZ, M-TR, and $\mathrm{OH}$ provided a critical review of the data and manuscript. All authors contributed to the article and approved the submitted version.

\section{FUNDING}

This work was supported by the APHP (Assistance Publique des Hopitaux de Paris), and the "Institut National du Cancer". FZ was supported by grants from Fondation ARC pour la Recherche contre le Cancer and from The Secular Society (TSS). VAA was recipient of a $\mathrm{PhD}$ fellowship from TSS.

\section{ACKNOWLEDGMENTS}

We are grateful to the clinical investigation center (CIC) of Necker hospital for their implication in clinical studies. We thank Lucienne Chatenoud (INSERM U1013, Paris, France) for providing congenic (CD45.1), Foxp $3^{\mathrm{GFP}}$ and CD45.1-Foxp $3{ }^{\mathrm{GFP}}$ B6 mice. We thank Elke Schneider for editing the manuscript.

\section{SUPPLEMENTARY MATERIAL}

The Supplementary Material for this article can be found online at: https://www.frontiersin.org/articles/10.3389/fimmu.2020. 607180/full\#supplementary-material 


\section{REFERENCES}

1. Anderlini P, Körbling M. The use of mobilized peripheral blood stem cells from normal donors for allografting. Stem Cells (1997) 15:9-17. doi: 10.1002/ stem. 150009

2. D’Aveni M, Rossignol J, Coman T, Sivakumaran S, Henderson S, Manzo T, et al. G-CSF mobilizes CD34+ regulatory monocytes that inhibit graftversus-host disease. Sci Transl Med (2015) 7:281ra42. doi: 10.1126/ scitranslmed.3010435

3. D’Aveni M, Notarantonio AB, Bertrand A, Boulangé L, Pochon C, Rubio MT. Myeloid-Derived Suppressor Cells in the Context of Allogeneic Hematopoietic Stem Cell Transplantation. Front Immunol (2020) 11:989. doi: 10.3389/fimmu.2020.00989

4. Cohen JL, Trenado A, Vasey D, Klatzmann D, Salomon BL. CD4(+)CD25(+) immunoregulatory $\mathrm{T}$ Cells: new therapeutics for graft-versus-host disease. J Exp Med (2002) 196:401-6. doi: 10.1084/jem.20020090

5. Hoffmann P, Ermann J, Edinger M, Fathman CG, Strober S. Donor-type CD4 $(+) \mathrm{CD} 25(+)$ regulatory T cells suppress lethal acute graft-versus-host disease after allogeneic bone marrow transplantation. J Exp Med (2002) 196:389-99. doi: $10.1084 /$ jem.20020399

6. Trenado A, Sudres M, Tang Q, Maury S, Charlotte F, Grégoire S, et al. Ex vivo-expanded $\mathrm{CD} 4+\mathrm{CD} 25+$ immunoregulatory $\mathrm{T}$ cells prevent graft-versushost-disease by inhibiting activation/differentiation of pathogenic $\mathrm{T}$ cells. J Immunol (2006) 176:1266-73. doi: 10.4049/jimmunol.176.2.1266

7. Kared H, Adle-Biassette H, Fö̈s E, Masson A, Bach J-F, Chatenoud L, et al. Jagged2-expressing hematopoietic progenitors promote regulatory $\mathrm{T}$ cell expansion in the periphery through notch signaling. Immunity (2006) 25:823-34. doi: 10.1016/j.immuni.2006.09.008

8. Kared H, Leforban B, Montandon R, Renand A, Layseca Espinosa E, Chatenoud L, et al. Role of GM-CSF in tolerance induction by mobilized hematopoietic progenitors. Blood (2008) 112:2575-8. doi: 10.1182/blood2008-02-140681

9. Korniotis S, D'Aveni M, Hergalant S, Letscher H, Tejerina E, Gastineau P, et al. Mobilized multipotent hematopoietic progenitors stabilize and expand regulatory $\mathrm{T}$ cells to protect against autoimmune encephalomyelitis. Front Immunol (2020) 11:607175. doi: 10.3389/fimmu.2020.607175

10. Lataillade J-J, Clay D, David C, Boutin L, Guerton B, Drouet M, et al. Phenotypic and functional characteristics of $\mathrm{CD} 34+$ cells are related to their anatomical environment: is their versatility a prerequisite for their bioavailability? J Leukoc Biol (2005) 77:634-43. doi: 10.1189/jlb.0504273

11. Li Q, Zhai Z, Xu X, Shen Y, Zhang A, Sun Z, et al. Decrease of CD4(+)CD25 (+) regulatory $\mathrm{T}$ cells and TGF-beta at early immune reconstitution is associated to the onset and severity of graft-versus-host disease following allogeneic haematogenesis stem cell transplantation. Leuk Res (2010) 34:115868. doi: 10.1016/j.leukres.2010.03.017

12. Baecher-Allan C, Brown JA, Freeman GJ, Hafler DA. CD4+CD25high regulatory cells in human peripheral blood. J Immunol (2001) 167:1245-53. doi: 10.4049/jimmunol.167.3.1245

13. Bremm M, Huenecke S, Lehrnbecher T, Ponstingl E, Mueller R, Heinze A, et al. Advanced flowcytometric analysis of regulatory T cells: CD127 downregulation early post stem cell transplantation and altered Treg/CD3 (+)CD4(+)-ratio in severe GvHD or relapse. J Immunol Methods (2011) 373:36-44. doi: 10.1016/j.jim.2011.07.018

14. Magenau JM, Qin X, Tawara I, Rogers CE, Kitko C, Schlough M, et al. Frequency of $\mathrm{CD} 4(+) \mathrm{CD} 25(\mathrm{hi}) \mathrm{FOXP} 3(+)$ regulatory $\mathrm{T}$ cells has diagnostic and prognostic value as a biomarker for acute graft-versus-hostdisease. Biol Blood Marrow Transplant (2010) 16:907-14. doi: 10.1016/j.bbmt. 2010.02.026

15. Taylor PA, Lees CJ, Blazar BR. The infusion of ex vivo activated and expanded $\mathrm{CD} 4(+) \mathrm{CD} 25(+)$ immune regulatory cells inhibits graft-versus-host disease lethality. Blood (2002) 99:3493-9. doi: 10.1182/blood.v99.10.3493

16. Ferreira LMR, Muller YD, Bluestone JA, Tang Q. Next-generation regulatory T cell therapy. Nat Rev Drug Discov (2019) 18:749-69. doi: 10.1038/s41573019-0041-4

17. Putnam AL, Safinia N, Medvec A, Laszkowska M, Wray M, Mintz MA, et al. Clinical grade manufacturing of human alloantigen-reactive regulatory $\mathrm{T}$ cells for use in transplantation. Am J Transplant (2013) 13:3010-20. doi: 10.1111/ ajt.12433
18. Lee K, Nguyen V, Lee KM, Kang SM, Tang Q. Attenuation of donor-reactive T cells allows effective control of allograft rejection using regulatory $\mathrm{T}$ cell therapy. Am J Transplant (2014) 14:27-38. doi: 10.1111/ajt.12509

19. Banerjee DK, Dhodapkar MV, Matayeva E, Steinman RM, Dhodapkar KM. Expansion of FOXP3high regulatory T cells by human dendritic cells (DCs) in vitro and after injection of cytokine-matured DCs in myeloma patients. Blood (2006) 108:2655-61. doi: 10.1182/blood-2006-03-011353

20. Golovina TN, Mikheeva T, Suhoski MM, Aqui NA, Tai VC, Shan X, et al. CD28 costimulation is essential for human $\mathrm{T}$ regulatory expansion and function. J Immunol (2008) 181:2855-68. doi: 10.4049/jimmunol.181.4. 2855

21. Brunstein CG, Miller JS, Cao Q, McKenna DH, Hippen KL, Curtsinger J, et al. Infusion of ex vivo expanded T regulatory cells in adults transplanted with umbilical cord blood: safety profile and detection kinetics. Blood (2011) 117:1061-70. doi: 10.1182/blood-2010-07-293795

22. Hoffmann P, Eder R, Boeld TJ, Doser K, Piseshka B, Andreesen R, et al. Only the CD45RA+ subpopulation of $\mathrm{CD} 4+\mathrm{CD} 25$ high $\mathrm{T}$ cells gives rise to homogeneous regulatory T-cell lines upon in vitro expansion. Blood (2006) 108:4260-7. doi: 10.1182/blood-2006-06-027409

23. Godfrey WR, Spoden DJ, Ge YG, Baker SR, Liu B, Levine BL, et al. Cord blood $\mathrm{CD} 4(+) \mathrm{CD} 25(+)$-derived $\mathrm{T}$ regulatory cell lines express FoxP3 protein and manifest potent suppressor function. Blood (2005) 105:750-8. doi: 10.1182/ blood-2004-06-2467

24. Hippen KL, Harker-Murray P, Porter SB, Merkel SC, Londer A, Taylor DK, et al. Umbilical cord blood regulatory T-cell expansion and functional effects of tumor necrosis factor receptor family members OX40 and 4-1BB expressed on artificial antigen-presenting cells. Blood (2008) 112:2847-57. doi: 10.1182/ blood-2008-01-132951

25. Koreth J, Matsuoka K, Kim HT, McDonough SM, Bindra B, Alyea EP, et al. Interleukin-2 and regulatory T cells in graft-versus-host disease. $N$ Engl J Med (2011) 365:2055-66. doi: 10.1056/NEJMoa1 108188

26. Su X, Wang Q, Guo W, Pei X, Niu Q, Liu M, et al. Loss of Lkb1 impairs Treg function and stability to aggravate graft-versus-host disease after bone marrow transplantation. Cell Mol Immunol (2020) 17:483-95. doi: 10.1038/ s41423-019-0312-3

27. Komatsu N, Okamoto K, Sawa S, Nakashima T, Oh-hora M, Kodama T, et al. Pathogenic conversion of Foxp3+ T cells into TH17 cells in autoimmune arthritis. Nat Med (2014) 20:62-8. doi: 10.1038/nm.3432

28. Zhou X, Bailey-Bucktrout SL, Jeker LT, Penaranda C, Martínez-Llordella M, Ashby $\mathrm{M}$, et al. Instability of the transcription factor Foxp3 leads to the generation of pathogenic memory T cells in vivo. Nat Immunol (2009) 10:1000-7. doi: 10.1038/ni.1774

29. Gao Y, Tang J, Chen W, Li Q, Nie J, Lin F, et al. Inflammation negatively regulates FOXP3 and regulatory T-cell function via DBC1. Proc Natl Acad Sci USA (2015) 112:E3246-54. doi: 10.1073/pnas.1421463112

30. Koch MA, Tucker-Heard G, Perdue NR, Killebrew JR, Urdahl KB, Campbell DJ. The transcription factor T-bet controls regulatory T cell homeostasis and function during type 1 inflammation. Nat Immunol (2009) 10:595-602. doi: $10.1038 /$ ni.1731

31. Ganesh BB, Cheatem DM, Sheng JR, Vasu C, Prabhakar BS. GM-CSF-induced CD11c+CD8a-dendritic cells facilitate Foxp3+ and IL-10+ regulatory T cell expansion resulting in suppression of autoimmune thyroiditis. Int Immunol (2009) 21:269-82. doi: 10.1093/intimm/dxn147

32. Ganesh BB, Bhattacharya P, Gopisetty A, Sheng J, Vasu C, Prabhakar BS. IL- $1 \beta$ promotes TGF- $\beta 1$ and IL-2 dependent Foxp3 expression in regulatory T cells. PLoS One (2011) 6:e21949. doi: 10.1371/journal.pone. 0021949

33. Mercer F, Kozhaya L, Unutmaz D. Expression and function of TNF and IL-1 receptors on human regulatory T cells. PLoS One (2010) 5:e8639. doi: 10.1371/ journal.pone.0008639

34. Jankovic D, Ganesan J, Bscheider M, Stickel N, Weber FC, Guarda G, et al. The Nlrp3 inflammasome regulates acute graft-versus-host disease. J Exp Med (2013) 210:1899-910. doi: 10.1084/jem.20130084

35. Antin JH, Weisdorf D, Neuberg D, Nicklow R, Clouthier S, Lee SJ, et al. Interleukin-1 blockade does not prevent acute graft-versus-host disease: results of a randomized, double-blind, placebo-controlled trial of interleukin-1 receptor antagonist in allogeneic bone marrow transplantation. Blood (2002) 100:3479-82. doi: 10.1182/blood-2002-03-0985 
Conflict of Interest: The authors declare that the research was conducted in the absence of any commercial or financial relationships that could be construed as a potential conflict of interest.

Copyright (C) 2021 D’Aveni, Notarantonio, Agbogan, Bertrand, Fouquet, Gastineau, Garfa-Traoré, De Carvalho, Hermine, Rubio and Zavala. This is an open-access article distributed under the terms of the Creative Commons Attribution License (CC BY). The use, distribution or reproduction in other forums is permitted, provided the original author(s) and the copyright owner(s) are credited and that the original publication in this journal is cited, in accordance with accepted academic practice. No use, distribution or reproduction is permitted which does not comply with these terms. 